\title{
Por uma atenção diferenciada e menos desigual: o caso do Distrito Sanitário Especial Indígena da Bahia
}

\section{For differentiated and less uneven health care practices: the case of the Special Indigenous Sanitary District of Bahia}

\author{
Sara Emanuela de Carvalho Mota \\ Ministério da Saúde. Secretaria Especial de Saúde Indígena. \\ Brasília, DF, Brasil. \\ E-mail: saraesophia®gmail.com
}

\section{Mônica Nunes}

Universidade Federal da Bahia. Salvador, BA, Brasil. E-mail: nunesm®ufba.br

\section{Correspondência}

Sara Emanuela de Carvalho Mota

Alameda Carrara, 336, ap. 603, bloco B, Pituba. Salvador, BA, Brasil. CEP 41830-590.

\section{Resumo}

Nesse estudo buscou-se conhecer os significados do princípio da "atenção diferenciada" por meio da análise dos enunciados e da observação das práticas de gestores do Subsistema de Atenção à Saúde dos Povos Indígenas na Bahia, a fim de revelar as bases sociais, políticas e culturais que os sustentam e analisar como contribuem, ou não, para a sua operacionalização. Parte-se do pressuposto de que a prestação de ações de atenção à saúde efetivamente diferenciadas, que considerem as especificidades socioculturais dos povos indígenas e sua medicina tradicional, pode contribuir para maior resolutividade do cuidado à saúde desses povos e mitigação de algumas implicações de determinantes sociais sobre os modos de viver, adoecer e morrer na população indígena. Optou-se pela realização de um estudo qualitativo, de abordagem etnográfica, com aplicação das técnicas de observação participante e de entrevistas semiestruturadas entre gestores do Subsistema na Bahia. A coleta de informações ocorreu entre setembro de 2014 e março de 2017. As narrativas revelaram frequentemente um tom retórico da ideia de "atenção diferenciada" como uma iniciativa de respeito às especificidades culturais indígenas, as quais foram mais insistentemente utilizadas como justificativa para a não realização de práticas diferenciadas de cuidado (por exemplo, protocolos específicos). A presença de indígenas na gestão contribuiu para a produção de práticas mais contextualizadas e orientadas para os problemas vivenciados pelas comunidades, mas o esforço de legitimação nesse espaço social 
ratifica a hegemonia "branca" na pauta principal de discussões.

Palavras-chave: Saúde de Populações Indígenas; Desigualdades em Saúde; Política de Saúde.

\section{Abstract}

In this study, we sought to know the meanings of the principle of "differentiated health care" through the analysis of narratives and practices from managers of the Subsystem of Indigenous People's Health Care in Bahia, Brazil, to reveal how their social, political, and cultural bases can contribute or not to its operationalization. It is assumed that the provision of effectively differentiated health care actions, which consider the socio-cultural specificities of indigenous peoples and their traditional medicine, can contribute to a greater resolution of health services targeted for these peoples and mitigation of some social determinants of their ways of living and dying. Thus, a qualitative study with an ethnographic approach was developed, using participant observation techniques and semistructured interviews with managers of the Subsystem in Bahia. Data collection took place between September 2014 and March 2017. The narratives often revealed a rhetorical tone of the idea of "differentiated health care" as an initiative to respect indigenous cultural specificities, which were insistently used as a justification for not conducting differentiated practices (as specific protocols, for example). The presence of indigenous people in the management contributed for producing more contextualized practices, oriented to the problems experienced by the communities, but the effort to legitimize themselves in this social space ratifies a "white" hegemony in the main topic of discussions.

Keywords: Health of Indigenous Peoples; Health Inequalities; Health Policy.

\section{Introdução}

As lutas de grupos minoritários por reconhecimento social e pelo estabelecimento de uma ação estatal que combata a discriminação, favoreça a igualdade e permita a convivência entre populações de origens culturais e étnicas diferentes fazem parte da paisagem político-cultural do mundo contemporâneo (Neves, 2005). Elas têm suscitado discussões em torno de temáticas como multiculturalismo, direitos culturais e políticas afirmativas direcionadas a grupos sociais discriminados com uma projeção inusitada.

A ideia de multiculturalismo é, todavia, bastante contestada e atravessada por tensões. Para tentar resolver esse dilema, alguns autores têm se debruçado sobre o conceito de reconhecimento como instrumento heurístico interessante para abordar processos alternativos de construção de novas cidadanias, para a compreensão dos possíveis efeitos de políticas públicas que se pretendem inclusivas, ou para diagnosticar padrões simbólicos desrespeitosos (Mendonça, 2007).

Nesse estudo, recorre-se ao contributo teórico de Boaventura de Sousa Santos (2000a, 200ob, 2009, 2010) ao reconhecer que vivemos hoje em um lugar multicultural onde se exerce uma constante hermenêutica de suspeição contra supostos universalismos ou totalidades. Assim, sendo múltiplas as faces da dominação, serão múltiplas as resistências e os agentes que as protagonizam (Santos, 20oob). Ao situar o tema do multiculturalismo num jogo de tensões entre a exigência do reconhecimento da diferença e de redistribuição que permita a realização da igualdade, o autor propõe concepções alternativas de cidadanias e de dignidade humana, assentes em uma sociologia das ausências, capaz de identificar os silêncios e ignorâncias que definem as incompletudes das culturas, das experiências e dos saberes, e em uma teoria da tradução que permita criar inteligibilidades mútuas, articular diferenças e equivalências entre experiências, culturas, formas de opressão e de resistência (Santos; Nunes, 2003).

A escolha por essa construção teórica pretende, portanto, ratificar o sentido emancipatório que o sociólogo confere à ideia de multiculturalismo e 
aproximar-se das experiências sociais de novas cidadanias por ele estudadas em um exercício crítico contínuo de desfamiliarização em relação a tudo o que está estabelecido e é convencionalmente aceito, em busca de um momento de suspensão necessário para criar uma nova familiaridade, um novo senso comum, um senso comum-emancipação (Santos, 2000a) com o intuito de lançar luz sobre a análise de narrativas e práticas de profissionais que atuam na gestão de uma política pública específica, direcionada à atenção à saúde dos povos indígenas.

A diversidade cultural apresenta um importante desafio para os serviços de saúde em todas as sociedades do mundo (Kirmayer; Rousseau; Guzder, 2014). No Brasil, com o objetivo de garantir os direitos relativos à diversidade cultural indígena, foi criado um Subsistema de Atenção à Saúde Indígena (Sasi) sob a bandeira da "atenção diferenciada", ou seja, a provisão de serviços de saúde por meio de uma estrutura separada, porém parte integrante do Sistema Único de Saúde (SUS), que articulam com, ou incorporam, as práticas tradicionais das comunidades (Diehl; Langdon, 2015).

O estudo da gestão da Política Nacional de Atenção à Saúde dos Povos Indígenas (PNASPI) nos insere do outro lado da linha abissal produzida pelo pensamento moderno ocidental que cinde a realidade social em dois universos, um "do lado de cá da linha”, visível, relevante; e o "do outro lado da linha", invisível, inexistente, radicalmente excluído do universo compreensível, em que são mantidas as formas de conhecimento populares, leigas e indígenas, no qual não há conhecimento real, apenas crenças, magia, idolatria, intuição e subjetividade, que podem vir a tornar-se matéria prima para a inquirição científica (Santos, 2009). Ademais, como nos alerta Verdum (2009), nos situa em um multiculturalismo "bem-comportado" instituído pelo Estado brasileiro, que se ocupa da diversidade enquanto diferença cultural, em uma perspectiva essencialista, ao mesmo tempo em que ignora diferenças econômicas e sociopolíticas, reforçando os mecanismos de controle e domínio do poder do Estado Nacional e os interesses do capitalismo global sobre os territórios e os recursos naturais.

Nisso, coaduna com a percepção de Catherine Walsh (2009) de que as mais recentes conquistas constitucionais direcionadas aos povos indígenas sugerem um esforço de reacomodação da colonialidade do poder por meio de um discurso (neo)liberal multiculturalista que tem como um dos seus elementos constitutivos e fundantes o racismo nas relações de dominação e que, ao assumir a lógica da "diferença", esvazia seu conteúdo de significado efetivo e oculta os mecanismos para superação das novas estratégias de subordinação.

A incorporação jurídica dos direitos dos povos indígenas no Brasil não representou, portanto, a superação das desigualdades epistêmicas ou a ruptura com as estruturas de poder, de matriz colonial, que permitem a manutenção da perspectiva hegemônica (eurocêntrica) do saber, anulando distintas cosmovisões. No campo das políticas públicas, formas de acesso diferenciado a algumas ações e serviços costumam operar de maneira essencialmente funcional, pouco atenta aos alicerces para a construção de uma sociedade mais equitativa e multicultural. Em relação às políticas de saúde, mais especificamente, se mantêm intactos os principais processos pelos quais atuam os determinantes sociais sobre os contextos de vida e os indicadores epidemiológicos da saúde indígena no país.

Caracterizado no âmbito da PNASPI como um modelo de organização de serviços atento à dinamicidade dos territórios indígenas, o Distrito Sanitário Especial Indígena da Bahia (DSEIBA), onde se desenvolveu esse estudo, abrangia 71 aldeias, localizadas em 27 municípios, que abrigavam indígenas de 14 etnias em 2012. Reflexo dessa dinamicidade, o território indígena sob a responsabilidade sanitária do DSEI-BA, em 2017, estava distribuído em 135 aldeias, localizadas em 30 municípios, onde vivem indígenas de 23 etnias. Dessas, apenas 29 terras indígenas estão em alguma fase do processo demarcatório da Fundação Nacional do Índio (Funai), sendo frequentes os conflitos fundiários entre indígenas e fazendeiros, movimentos migratórios e o movimento de "retomada", como é conhecida a reincorporação de parte do território que estava em posse de não índios, dentro da área indígena, gerando novos povoados, com lideranças e organização próprias.

Nas aldeias do estado vivem indígenas de 23 etnias, com características que diferem entre si e 
que distam do estereótipo do indígena que habita o imaginário popular brasileiro. Isso porque o processo de colonização lusitana contribuiu sobremaneira para o abrandamento dos contornos diacríticos de povos indígenas do Brasil, especialmente aqueles que habitavam a faixa litorânea da região do Nordeste do país, onde teve início. Os primeiros registros históricos afirmam que o primeiro contato interétnico entre colonizadores e a população, a que se chamou genericamente de "índios", se deu na costa baiana, onde viviam, há pelo menos onze mil anos, Tupinambás ou Tupiniquins, Gês, Tamoio ou Tapuia e os Kariri ou Kiriri (Tavares, 2009).

Inicialmente designados Tapuias, os indígenas da Costa do Descobrimento foram submetidos aos mais diversos e contraditórios esboços de uma ação indigenista de Estado, recaindo sobre si mais pesadamente o estigma da mistura, segundo afirma Maria do Rosário (Carvalho; Carvalho, 2012), ao estudar a categoria caboclo, atribuída indistintamente aos indígenas de diferentes etnias que ocupavam os limites da baía e que participa intensamente da construção da identidade nacional-baiana.

A tradição da oralidade na transmissão do conhecimento e da história dos povos indígenas contribuiu para sua inserção em um cenário quase folclórico. Em algumas províncias do Nordeste brasileiro, por volta da década de 1870 , a retórica oficial informava o desaparecimento dos índios, restando apenas remanescentes que preservavam algumas manifestações culturais (Oliveira, 2011). Um século antes, no governo de D. José I, o Marquês de Pombal propôs medidas de integração dos índios à sociedade portuguesa colonial, rompendo com a política de segregação implantada pelos missionários e visando anular a identidade étnica desses povos (Medeiros, 2011).

Mais recentemente, alguns autores têm abordado, sem embargo, o processo de etnogênese entre povos indígenas, com ênfase na região do Nordeste (Arruti, 2006; IBGE, 2012; Luciano, 2006; Mauro, 2013; Medeiros, 2011). Entendida como a construção de uma autoconsciência e identidade contra uma ação de desrespeito coletiva, com vistas ao reconhecimento e conquista de objetivos coletivos (Arruti, 2006), esse processo passa a ganhar amplitude a partir da década de 1980, quando surgem importantes coletivos do movimento indígena organizado, e se intensifica com as alterações da Constituição de 1988, quando o valor sociocultural passa a ter outra referência e valorizam-se cada vez mais as práticas tradicionais, os rituais e as línguas originárias (Luciano, 2006).

Esse processo de reafirmação étnica concorre para justificar o crescimento vertiginoso da população indígena brasileira de acordo com os registros censitários. A população que se autodeclara indígena foi incorporada como categoria no censo nacional a partir de 1991 e apresentou o aumento de aproximadamente $150 \%$ em uma década, no período entre 1991 e 2000. Em 2010, a população que se autodeclarava indígena somava cerca de 817 mil pessoas em todo o país, concentrada sobretudo na região Norte, seguida pela região Nordeste, que conta com a maior população de Indígenas em áreas urbanas, fora de aldeias (IBGE, 2012). A Bahia possui a segunda maior população indígena do Nordeste e a maior população fora de aldeias na região, com aproximadamente $72 \%$ da população indígena no estado vivendo fora de terras indígenas (IBGE, 2010). Essa condição dificulta sobremaneira o acesso aos serviços de saúde no âmbito do Subsistema, uma vez que esses são organizados exclusivamente em terras indígenas.

Entre os povos que ocupam o território baiano originariamente temos Pataxó Hã Hãe, Tumbalalá, Tuxá, Kaimbé, Kiriri, Pataxó e Tupinambá, sendo esses dois últimos os povos que concentram as maiores populações indígenas do estado e as etnias com maior população fora de terras indígenas no país (IBGE, 2010). Além desses, são também assistidos pelo Subsistema na Bahia Atikuns, Fulni-ôs, Pankarús, Trukás, Tuxás, Tumbalalás, Kapinawás, Payayás, Pankararés, Kantarurés, Xukurus-Kariri, Jeripancós, Kariri-Xocós, Kambiwás e Pankararus. As características desses povos relacionam-se de maneira estreita com a trajetória de seus ancestrais e com o ambiente natural do seu território, que vai desde a Mata Atlântica do litoral da Costa do Descobrimento à caatinga do sertão baiano de Canudos.

Nesse contexto atuam 32 equipes multidisciplinares de saúde indígena, compostas por profissionais indígenas, sobretudo técnicos de 
enfermagem e agentes de saúde e saneamento, e profissionais não indígenas, principalmente médicos, enfermeiros e odontólogos. De acordo com a PNASPI, essas equipes devem prestar ações de

atenção à saúde dos indígenas de forma diferenciada, levando-se em consideração as especificidades culturais, epidemiológicas e operacionais desses povos no desenvolvimento e uso de tecnologias apropriadas por meio da adequação das formas ocidentais convencionais de organização de serviços. (Brasil, 2002, p. 6)

A despeito do que dispõe o texto da PNASPI, não há documentos oficiais que orientem no sentido da operacionalização dessa perspectiva diferenciada de atenção. Sobre isso, Garnelo (2014) analisou os dispositivos legais do SUS e do Subsistema sobre a assistência à saúde dos povos indígenas publicados entre 1990 e 2010 , e não encontrou aquele que se debruçasse mais atentamente sobre a diretriz da preparação para atuação em contexto intercultural, principal justificativa apresentada por Antônio Sérgio da Silva Arouca para a criação de um subsistema de saúde com enfoque diferenciado.

Na mesma esteira, Langdon (2004, p. 42) analisa as propostas da III Conferência Nacional de Saúde Indígena que reconhecem que o conceito de atenção diferenciada ainda tem que ser operacionalizado em esfera local e nos níveis secundários e terciários do SUS, afirmando que os profissionais não são capacitados para trabalhar com outras culturas.

Ao analisar Planos Distritais de Saúde Indígena, Garnelo conclui:

Os documentos normativos do Subsistema de Saúde Indígena são pródigos na repetição de princípios genéricos de ação (como preconizar, por exemplo, a articulação e o fortalecimento dos sistemas de medicina tradicional) que não se traduzem em atividades concretas nem nas programações anuais de atividades dos DSEI, nem nas práticas sanitárias das equipes. (Garnelo, 2004, p. 13)

A insuficiência de clareza acerca dos pressupostos que caracterizam a atenção diferenciada à saúde dos povos indígenas tem estimulado frequentes debates acerca dos rumos do Sasi-SUS. Propostas como a do Conselho Nacional de Secretários de Saúde, de integração do cuidado com a saúde dos povos indígenas às demais redes prioritárias de atenção, revelam a preocupação com os rumos da gestão das ações de saúde indígena no país e sinalizam para a necessidade de discutir "o que se entende por atenção diferenciada e até que ponto ela contribui ou não para a efetiva inserção, no SUS, do subsistema de atenção à saúde indígena" (Brasil, 2014, p. 15).

Ao se inserirem na atenção primária, essas equipes mergulham diariamente no cotidiano das comunidades, em seus territórios dispersos e marcados pela pobreza e conflitos fundiários, com visitas espaçadas e descontínuas devido à fragilidade dos serviços logísticos, quando realizam majoritariamente atendimentos de demanda espontânea por acidentes com animais peçonhentos, antirrábicos, doenças infectocontagiosas e relacionadas a arboviroses, e agravos associados à violência (Diasi, 2017). Além da deficiência dos serviços prestados, as condições sociais, econômicas e ambientais participam sobremaneira do perfil epidemiológico da população indígena na Bahia, o que assevera a necessidade de fortalecimento das ações de atenção básica.

Neste estudo, buscou-se conhecer os significados da categoria discursiva "atenção diferenciada" por maio da análise das narrativas e da observação das práticas de gestores do Subsistema de Atenção à Saúde dos Povos Indígenas na Bahia, a fim de revelar as bases sociais, políticas e culturais que os sustentam e analisar como contribuem, ou não, para a sua operacionalização. Parte-se do pressuposto de que a prestação de ações de atenção à saúde efetivamente diferenciadas, que considerem as especificidades socioculturais dos povos indígenas e a sua medicina tradicional, pode contribuir para maior resolutividade do cuidado à saúde desses povos e mitigação de algumas implicações de determinantes sociais sobre os modos de viver, adoecer e morrer na população indígena.

\section{Metodologia}

Optou-se pela realização de um estudo qualitativo, de abordagem etnográfica, com aplicação das 
técnicas de entrevistas semiestruturadas para o estudo das narrativas dos sujeitos em relação ao objeto da pesquisa, e de observação participante, com registro em diário de campo, das práticas dos diferentes agentes que se articulam nessa complexa rede de relações sociais que envolve o exercício da gestão de uma política pública que se organiza em diferentes contextos indígenas, orientados por textos institucionais dúbios. O campo de observação foi composto por espaços colegiados de gestão instituídos no âmbito do DSEI-BA, órgão ligado à Secretaria Especial de Saúde Indígena do Ministério da Saúde, entre setembro de 2014 e março de 2017. Cumpre ressaltar que a pesquisadora que realizou essa etapa da pesquisa fazia parte do grupo de gestores do Distrito, à época, de modo que seu acesso aos espaços de observação compunha a rotina do serviço.

A opção pelo método qualitativo de investigação justifica-se pela busca de um conhecimento intersubjetivo, descritivo e compreensivo, a partir das atitudes de sentido que os agentes conferem as suas ações, como propõe Santos (2010), e como essas influenciam o seu fazer cotidiano, considerando que a ação individual provoca e articula-se com outras ações em uma cadeia infinita, impregnada por forças institucionais que exercem menor ou maior pressão a depender da posição e/ou espaço ocupado por cada ator social. Para Langdon (2016), a metodologia qualitativa é capaz de produzir resultados com maior potencial para pensar políticas públicas em contextos de diversidade e saberes culturais.

A abordagem antropológica é aplicada com o intuito de contribuir para uma reflexão crítica sobre as políticas públicas, desde a macro à micropolítica das práticas cotidianas dos agentes que atuam em nome do Estado, bem como de confrontar as diretrizes dessas políticas com as experiências sociais dos sujeitos, como bem advogam Langdon, Grisotti e Maluf (2016).

A aprovação do projeto de pesquisa pelo Comitê de Ética do Instituto de Saúde Coletiva se deu pelo Parecer $n^{0}$ 1.849.830. Foram entrevistados 26 gestores do Subsistema de Atenção à Saúde Indígena da Bahia, sendo 9 coordenadores técnicos dos Polos-Base localizados em municípios do interior do estado, e 17 gestores do nível central, lotados na sede do Distrito, localizada na capital, distribuídos entre os setores de atenção à saúde, gestão de pessoas e coordenação distrital. A identidade dos colaboradores foi preservada e seus nomes foram substituídos por códigos alfanuméricos. Os sujeitos dos enunciados estão caracterizados quanto à pertença étnica e tempo de serviço no DSEI-BA.

\section{Sobre trajetórias dos sujeitos envolvidos na gestão do Subsistema de Atenção à Saúde Indígena na Bahia}

Até o final de 2016, o DSEI-BA tinha um quadro funcional com 767 profissionais distribuídos entre a sede do Distrito e as unidades descentralizadas, sendo 96 servidores estatutários, um cargo de confiança, 18 médicos do Programa Mais Médicos, 201 profissionais terceirizados e 451 profissionais contratados mediante convênio com uma Organização da Sociedade Civil de Interesse Público (Oscip), com o objetivo de fornecer força de trabalho para atuação na saúde indígena.

Cabe destacar que, entre os profissionais contratados pela OSCIP para atuar no Subsistema na Bahia, 299 (66\%) são indígenas, enquanto entre os servidores públicos, apenas um (6\%) é indígena, de modo que a contratação mediante convênio tem permitido o maior acesso desses povos a cargos nas equipes de saúde e na gestão do DSEI-BA. Ademais, o movimento indígena organizado tem pleiteado a participação nos mais elevados cargos da hierarquia institucional, com êxito neste caso, o que concorre para justificar a escolha desse Distrito como estudo de caso para as questões afetas à efetivação do diálogo intercultural.

O grupo de sujeitos entrevistados envolveu diferentes formações profissionais, como enfermeiros, odontólogos, nutricionistas, assistentes sociais, psicólogos, sociólogos e pedagogos, com tempo de experiência na saúde indígena que variava de 1 a 15 anos. A maioria (64\%) foi contratada por meio de processo seletivo simplificado, composto por avaliação curricular e entrevista, sobretudo nos últimos cinco anos. Participam dessa seleção representantes do conselho social indígena local e técnicos da empresa contratante. 0 pertencimento 
étnico é avaliado como indicador no barema de pontuação para análise curricular e como critério de desempate entre candidatos, favorecendo a contratação de profissionais indígenas.

Os demais profissionais são servidores públicos estatutários, que ingressaram na Secretaria Especial de Saúde Indígena (Sesai) mediante concurso ou por indicação política, no caso dos cargos de confiança. Entre os entrevistados, 50\% eram servidores da extinta Fundação Serviços de Saúde Pública que se fundiu à Superintendência de Campanhas de Saúde Pública para compor a Fundação Nacional de Saúde (Funasa), a partir de 1991. Na oportunidade em que esta assumiu a responsabilidade pela gestão do Subsistema, esses servidores já faziam parte do seu quadro funcional e participaram ativamente do processo de constituição do DSEI da Bahia.

$\mathrm{O}$ aproveitamento da estrutura física e do quadro de servidores da Funai e Funasa para a Sesai permitiu também a transferência de uma mentalidade tutelar em relação à participação dos indígenas no Sistema Único de Saúde. Distantes da inspiração sanitária que orientou a criação do Subsistema, os profissionais daquelas fundações atuavam como se a sua missão institucional fosse oferecer aos povos indígenas uma espécie de "plano de saúde privado", todavia financiado com recursos públicos.

Esses aspectos da implantação do DSEI da Bahia são aqui tratados pela observação de que o contexto descrito influencia até os dias de hoje as práticas e os enunciados dos servidores entrevistados que passaram pela transição interinstitucional, justificando por vezes a resistência por parte de gestores do SUS em relação ao Subsistema, desenvolvido em sua opinião para garantir "privilégios" de acesso aos povos indígenas, substituindo o princípio universalista do SUS por um viés privatista.

Além da dimensão do acesso, uma das principais justificativas para criação do Subsistema foi a constatação da necessidade de preparação de recursos humanos para atuação em contexto intercultural e de articulação dos sistemas tradicionais indígenas de saúde, traduzida mais tarde em diretrizes da PNASPI. Essa Política aponta o Programa de Formação de Agentes Indígenas de
Saúde como estratégia de “apropriação, pelos povos indígenas, de conhecimentos e recursos técnicos da medicina ocidental, não de modo a substituir, mas de somar ao acervo de terapias e outras práticas culturais próprias, tradicionais ou não" (Brasil, 2002, p. 15).

O texto da Política prevê ainda a realização de cursos de atualização/aperfeiçoamento/ especialização como "instrumento fundamental de adequação das ações dos profissionais de saúde do SUS às especificidades da atenção à saúde dos povos indígenas e às novas realidades técnicas, legais, políticas e de organização dos serviços" (Brasil, 2002, p.16). Entre os profissionais que participaram da pesquisa, $28 \%$ declararam já ter participado de algum curso específico sobre populações indígenas, a maioria no último ano. Entre os servidores que migraram da Funasa para a Sesai, não houve caso de participação em curso de formação com a temática da saúde indígena, apesar do maior tempo de experiência na atenção à saúde indígena.

\section{A polissemia em torno da Atenção Diferenciada à Saúde dos Povos Indígenas}

O estudo das narrativas e práticas de agentes envolvidos na gestão do Subsistema justifica-se a partir da compreensão de que uma abordagem diferenciada só se concretiza através da práxis dos sujeitos, orientada por racionalidades diversas, de acordo com trajetórias individuais, paradigmas epistemológicos, contexto social, político e econômico, recursos e tecnologias disponíveis, relações sociais e de poder, entre outros. Sobre isso, Langdon nos lembra que os atores sociais têm capacidade de agência no processo de construção e articulação de conceitos e práticas ligados à saúde/ doença, os quais interagem por meio das relações sociais e recombinam elementos das mais diferentes esferas, desde o acúmulo de saberes e a autonomia dos sujeitos até os fatores globais que influenciam diretamente as situações locais (Langdon, 2016)

Pesquisas anteriores (Chaves; Cardoso; Almeida, 2006; Garnelo; Macedo; Brandão, 2003; Langdon, 2004) concluem que os documentos normativos que regem o Subsistema utilizam princípios genéricos ao se referirem à atenção diferenciada à saúde, 
que não se traduzem em atividades concretas nas programações anuais de atividades de Distritos Sanitários de Saúde Indígena, vigorando, de modo geral, um modelo campanhista de assistência à saúde, caracterizado pelo deslocamento pouco regular de equipes de saúde para as aldeias, com ações descontínuas, fragmentadas e sem articulação com os sistemas de medicinas tradicionais.

As narrativas analisadas neste estudo revelaram frequentemente um tom retórico e quase dogmático da ideia de "atenção diferenciada" como uma iniciativa de respeito à cultura e à medicina tradicional indígenas. As especificidades culturais foram insistentemente utilizadas não como justificativa para a realização de práticas diferenciadas de atenção, a exemplo da construção de protocolos específicos de atenção que contemplem diferentes concepções de pessoa, ciclos de vida, saúde, adoecimento e morte entre os povos indígenas, ou ainda de diretrizes que orientem os profissionais de saúde para a construção conjunta dos projetos terapêuticos com os cuidadores tradicionais, mas sobretudo como explicação para o que não se faz em termos de organização da estratégia de atenção à saúde, a exemplo da falta de critérios para parametrização das equipes em relação aos territórios e populações assistidos.

Evocadas como uma espécie de barreira, que encerra as possibilidades de reorganização dos processos de trabalho e da adequação das práticas de cuidado das equipes multidisciplinares, as especificidades culturais são tratadas como um conceito esvaziado de sentido, com pouca ou nenhuma associação aos aspectos diacríticos do ser indígena. Pelo contrário, esses aspectos, quando abordados, foram acompanhados da ideia de perda ou abandono, em contraste com a imagem estereotipada revelada nas categorias "índio-índio" e "índio mesmo", cujas características remontam aos povos indígenas da Região Norte do país, ou ainda àqueles descritos pelos primeiros colonizadores.

A cultura está um pouco esquecida, até por conta dos conflitos que eles sofreram de uns tempos atrás pra cá, que eles tiveram que acabar escondendo a cultura que eles aprenderam na infância para se esconder mesmo da civilização. Então muito da cultura está se perdendo e isso a gente observa muito na comunidade. A gente não vê muito o uso da erva medicinal, por exemplo, já acabou. (G4, não indígena, mais de cinco anos no DSEI)

Aí sim [na Região Norte] se diferencia a equipe que trabalha com população indígena da equipe da saúde da família. Por causa da língua, da cultura, mas aqui [na Bahia] eu não percebo muita diferença. (G11, não indígena, menos de cinco anos no DSEI)

Mas os nossos indígenas, que são bastante aculturados, urbanizados mesmo, eles usaram esse sistema antes. Antes do subsistema, eles usaram o SUS. Tanto é que, depois do Subsistema, muitos voltaram para as suas aldeias. (G19, não indígena, mais de 10 anos no DSEI)

Quando questionados sobre a presença de cuidadores tradicionais nos territórios indígenas, as respostas foram correntemente relacionadas ao passado, sugerindo que as práticas tradicionais de cuidado seguiam progressivamente sendo substituídas pelo elenco de tecnologias disponíveis nos serviços de saúde. Cumpre destacar, neste ponto, que segundo relatório técnico elaborado em 2017 pela Divisão de Atenção à Saúde Indígena do Distrito, existiam 38 pajés, 52 parteiras, 130 rezadeiras e 85 benzedeiras que realizavam práticas tradicionais de cuidado em todo o território adstrito ao DSEI-BA e participavam ativamente dos itinerários terapêuticos dos povos indígenas assistidos.

Eu não vejo essa medicina tradicional, que éfalada pela gente, entre eles não. O que eu vejo é um consumo exacerbado de medicamento, não vejo essa consulta ao pajé, isso eu não vejo aqui não. Exceto aqui em Banzaê. No resto, eu não consegui perceber não. Eu acho que a busca pelo médico, pelo remédio, é muito mais forte do que a medicina tradicional. (G8, não indígena, mais de 10 anos no DSEI)

A fragilidade no desenvolvimento de competências cognitivas entre os profissionais que permitam identificar práticas de cuidado em saúde baseadas em diferentes racionalidades, dificulta 
a permeabilização das já rígidas estruturas de gestão com vistas à elaboração de estratégias que articulem e integrem as práticas tradicionais de cura e aquelas ofertadas pelos serviços de saúde nos territórios indígenas.

Tais competências devem ser desenvolvidas a partir da reflexão crítica dos profissionais acerca de suas próprias práticas e das racionalidades que as orientam. Para isso, Fernández-Juárez (2010) sugere a adoção de uma política clara de formação em saúde intercultural para educadores, gestores e trabalhadores a fim de estabelecer uma massa crítica de profissionais capazes de propor e aplicar de maneira sensata critérios interculturais que contribuam para melhorar os indicadores de saúde das populações indígenas locais.

A forte presença de profissionais indígenas no grupo de trabalhadores e gestores do DSEI$\mathrm{BA}$, ao passo em que contribui para redirecionar as relações entre os agentes rumo ao diálogo intercultural, traz para o processo de tomada de decisão novas autoridades políticas e engendra outras dinâmicas ao tradicional ciclo de gestão das políticas públicas.

As relações de poder influenciam sobremaneira as relações estabelecidas entre os agentes imersos em um contexto intercultural, conforme Menéndez (2006). Entre os enunciados dos gestores entrevistados, assumiu destaque a percepção da presença indígena associada à forma de participação dos caciques e lideranças nos processos de tomada de decisão no âmbito do Distrito.

Como a gente está em território indígena, existe uma questão do poder. Então os trabalhadores da saúde indígena passam por situações de muita pressão, não só da instituição [...]. Porque a pressão que existe dentro do território indígena com relação à questão de que "sófica quem a liderança quiser", porque quem manda é cacique X ou cacique $Y$, e também quando, por alguma razão, esse cacique se sente desagradado por esse trabalhador e ele passa a correr um risco grande de perder o emprego, eu acho que isso afeta de forma imensurável esse processo de trabalho, porque começa a ser uma relação doentia. (G2, indígena, mais de cinco anos no DSEI)

Porque a gente estabeleceu que ia fazer seleção, mas, se o selecionado não fosse o indicado do cacique ou da comunidade indígena, ele não assumia. Ou, se o candidato aprovado for indígena, mas se ele não for da minha aldeia, for da aldeia X, ele não vai assumir. Quem tem poder équem manda na aldeia. Só assume se o cacique ou liderança quiser. Então, para a gente, que é servidor público, isso não é confortável. (G6, não indígena, mais de dez anos no DSEI)

Assim, ao ter como missão a oferta de serviços de atenção primária à saúde em território indígena, os profissionais se inserem em um contexto em que os princípios e regras da administração pública que orientam os gestores se confrontam com a autoridade política do cacique, legitimamente escolhido para representar os interesses da sua comunidade, administrar os conflitos e promover o "aconselhamento" aos seus membros a fim de (re)estabelecer a "ordem da aldeia". Na maioria dos casos, ele centraliza a autoridade política no território, mas há também comunidades indígenas na Bahia em que mais de um cacique disputam a centralidade do poder político.

Além da disputa política interna da aldeia, existem também na Bahia os movimentos indígenas que se organizam para disputar politicamente espaços de decisão para fora da aldeia, principalmente dentro da estrutura do estado, a saber, o Movimento Unido dos Povos e Organizações Indígenas da Bahia e o Movimento Indígena da Bahia. Nesse sentido, a presença indígena em cargos da estrutura hierárquica do DSEI representou uma importante conquista para esses povos e um desafio para a administração pública na medida em que trouxe para o cotidiano da gestão outra cosmovisão, não ocidental, dos processos de saúde e doença, impondo a necessidade do diálogo intercultural de modo a viabilizar o processo de tomada de decisões.

Por outro lado, a tentativa de conciliação entre o papel de gestor e a condição de parente ${ }^{1}$

1 Parente é a forma como se tratam e se reconhecem os indígenas da região. 
provocava por vezes conflitos referentes ao exercício concomitante das funções sociais de coordenação e de liderança indígena.

Eu penso que, no processo atual de democracia, não há condição das instâncias de governo fazerem algo sem a participação do usuário. Mas, por outro lado, a exigência de cumprimento legal do estado brasileiro, daquilo que é direito da população, exige um certo nível de concertação, de adequação para aquilo que é possível, considerando orçamento, estratégia política, com o que está colocado na lei. No entanto, para a compreensão entre o que está estabelecido, entre o que os índios querem e o que é possivel fazer, não havia um nível de esclarecimento total. (G26, indígena, menos de cinco anos no DSEI)

Eu não vejo problema em ter um gestor indígena, desde que ele se veja como um gestor, como um agente público. Se ele se vê apenas como usuário, aívai ser um problema. O que eu percebo do gestor indígena é que ele ficou em uma situação muito complicada, porque a cobrança sobre esse gestor indígena por parte do usuário éainda maior, porque, se ele cumpre o que a administração pública prevê, ele está fadado ao fracasso, porque a comunidade indígena passa a vê-lo não como um aliado, ele passa a servisto como mais uma pessoa contrária ao subsistema. (G6, não indígena, mais de 10 anos no DSEI)

Notou-se, durante o período de observação, um esforço de busca entre os gestores indígenas por legitimação naquele espaço social, na tentativa de aproximar-se do ideal de gestor público, ao passo em que se afastam do referencial de autoridade política reconhecido pelas comunidades indígenas, a saber, caciques e lideranças. Esse processo de busca de aceitação em um espaço de poder hegemonicamente composto por "brancos", todavia, não se deu nesse caso de maneira subordinada, obedecendo estritamente o modus operandi ocidental clássico; ao contrário, estava em curso um processo de transformação das práticas de gestão, mais contextualizadas e orientadas à produção de respostas para os problemas vivenciados pelas comunidades, e pautadas sobretudo nas relações de empatia, no respeito às lideranças indígenas como chefes de nações e no fortalecimento dos processos coletivos de tomada de decisão, com estímulo à maior autonomia dos agentes públicos. Não raro levava também a importantes entraves para a resolução de algumas pautas.

A confusão de expectativas em relação aos papéis desempenhados por indígenas na gestão se acirra diante da polissemia do princípio da "atenção diferenciada" e da sua proximidade com a ideia de excepcionalidade, frequentemente associada nas narrativas dos sujeitos ao gozo de privilégios no acesso a serviços públicos. Essa associação não é acidental e relaciona-se de maneira estreita a textos normativos que organizam o SUS, como o do Decreto $n^{0} 7 \cdot 508 / 2011$, que prevê que "a população indígena contará com regramentos diferenciados de acesso às ações e serviços de saúde, compatíveis com suas especificidades e com a necessidade de assistência integral à sua saúde, de acordo com disposições do Ministério da Saúde" (Brasil, 2011), ainda sem regulamentação. Outrossim, as narrativas dos profissionais com mais tempo de serviço remetiam reiteradamente à memória do período em que o Subsistema era gerido pela Funasa, quando os procedimentos de saúde eram adquiridos mediante a compra direta a serviços privados, sem os limites burocráticos do processo licitatório

A noção de atenção diferenciada nesse caso perde seus amplos contornos e a complexidade inerente à atuação em contexto intercultural e reduz-se à dimensão do acesso, supostamente "facilitado" para os pacientes indígenas. Essa apreensão produz tensões constantes sobre os serviços prestados na esfera do Subsistema, que não participam do fluxo de regulação do SUS e são demandados continuamente por serviços de média e alta complexidade, sob responsabilidade de outros níveis de gestão.

Houve ainda entre os profissionais entrevistados a concepção de que a atenção diferenciada constitui uma falha, uma anomalia dentro do SUS, descabida e desnecessária, uma vez que os serviços de saúde deveriam ser prestados indistintamente a todos os cidadãos brasileiros. A defesa desse ponto de vista, porém, não revelou uma aproximação óbvia com a ideia de negação de direitos aos povos indígenas, 
mas principalmente com o não reconhecimento de aspectos diacríticos do ser indígena que justifiquem a adoção de práticas diferenciadas de atenção à saúde.

Os povos indígenas são uma comunidade como outra qualquer, que tem as mesmas necessidades que as outras, como as ribeirinhas etc., porém demandam de modo diferente, de acordo com sua cultura, sua localização regional, e isso já é um diferencial, independente de ser índio ou não. (G19, não indígena, mais de 10 anos no DSEI)

E eu nunca me lamentei de não ter essa preparação para trabalhar com a saúde indígena, porque eu acho que a gente trabalha com saúde pública, então, pra mim, eu precisava encarar o índio como um paciente. (G6, não indígena, mais de 10 anos no DSEI)

Diehl e Langdon (2015), em estudo na Terra Indígena Kaingang, encontraram também essa relação entre a percepção de sinais diacríticos associados com a identidade indígena no Brasil e como isso se reflete diretamente na conduta das equipes de saúde que não observam essa diferenciação em relação à sociedade envolvente e, consequentemente, não veem como necessários serviços e ações culturalmente adequados.

A atenção diferenciada constitui, portanto, princípio da PNASPI, mas não dispõe de documentos oficiais que orientem os processos de gestão no sentido de conduzir a sua concretização a partir da organização dos processos de trabalho e das práticas cotidianas das equipes de saúde. Como afirma Esther Jean Langdon (2007), os esforços para oferecer atenção diferenciada, quando existem, ocorrem de maneira isolada, com forte tendência à "essencialização" das noções de cultura e tradição.

As profundas mudanças provocadas nas culturas de povos indígenas a partir do contato com populações não indígenas, de acordo com Gersen Baniwa, enfraqueceram as matrizes cosmológicas e míticas em torno das quais girava toda a dinâmica da vida tradicional (Luciano, 2006), tornando ainda mais complexo o desafio de construção de práticas de atenção culturalmente adequadas, em especial na Região Nordeste do país, onde esse contato durou mais tempo.

Nesse sentido, Langdon, Diehl e Dias-Scopel (2014) enfatizam que o grau de inserção do grupo indígena na sociedade envolvente e a compreensão das equipes multidisciplinares acerca do princípio da atenção diferenciada são aspectos que influenciam sobremaneira sua efetivação. Assim, a turbidez que envolve seu conceito, e sua operacionalização por meio das práticas dos sujeitos envolvidos na gestão e execução dos serviços de saúde dirigidos a populações indígenas, coloca em xeque a principal justificativa para a manutenção de um subsistema específico dentro do SUS, criado a partir do reconhecimento do

processo de saúde/doença dos povos indígenas como o resultado de determinantes socioeconômicos e culturais, que vão desde a integridade territorial e da preservação do meio ambiente, à preservação dos sistemas médicos tradicionais desses povos e da preservação da cultura como um todo. (Brasil, 1994, p. 11)

Diante do exposto, o esforço do sanitarista Sérgio Arouca em garantir a aprovação do texto legislativo que estabelece um modelo de atenção à saúde indígena pautado em uma "abordagem diferenciada e global, que contemple os aspectos de assistência à saúde, saneamento básico, nutrição, habitação, meio ambiente, demarcação de terras, educação sanitária e integração institucional" (Brasil, 1999, art. 19-F), esvai-se na miríade de significados que a noção de atenção diferenciada assume entre aqueles responsáveis por induzir transformações na postura etnocêntrica dos profissionais de saúde envolvidos na prestação de ações de assistência médico-sanitária aos povos indígenas, como prevê a proposta original do Projeto de Lei.

Torna-se imprescindível, portanto, definir o que o Estado brasileiro entende por atenção diferenciada à saúde, de forma participativa e dialogada com os diferentes povos indígenas do país, a fim de construir um conceito pleno de sentido compartilhado e capaz de se concretizar por meio das práticas dos agentes 
envolvidos na sua operacionalização. Sobretudo, é necessário que tal conceito traga de forma inerente ao seu conteúdo forte carga crítica, que implique os agentes e os convide insistentemente a repensar a matriz ideológica, epistemológica e social que orienta as suas práticas, a exercitar a alteridade e a desenvolver novas tecnologias de saber/poder que possam contribuir para atenuar as desigualdades em saúde como sugere Boccara (2015, p. 196) ao abordar o "problema indígena”.

\section{Considerações finais}

As desigualdades sociais e em saúde que marcam os processos de vida, adoecimento e morte em populações indígenas no Brasil são bastante conhecidas na saúde coletiva. Na epidemiologia são diversos os estudos que revelam os perversos indicadores de saúde entre populações indígenas, a exemplo das mais elevadas taxas de mortalidade infantil e suicídio. No eixo do planejamento e gestão, uma breve análise de planos municipais de saúde permite notar as dificuldades de integração entre o Subsistema e os serviços de saúde especializados ofertados pelo SUS que impõem graves constrangimentos ao acesso pelos povos indígenas. No que tange às ciências sociais em saúde, são extensas etnografias que buscam explicar as diferentes cosmovisões entre os povos indígenas, contribuindo para a adoção de práticas de cuidado culturalmente mais sensíveis.

É fundamental, entretanto, avançar na produção de investigações sobre as desigualdades epistêmicas que sustentam uma hierarquia de saberes que produz como invisível ou subalterno o conhecimento produzido sob outras racionalidades que extrapolam a indolência da ciência moderna, largamente descrita e analisada por alguns dos autores citados neste estudo. Essa estrutura de pensamento hierárquica e monocultural é responsável pela reprodução de padrões de relação de poder que se mantêm presentes até hoje em sociedades marcadas por um processo histórico de colonização e que construíram suas instituições sobre os alicerces do colonizador.

Os achados desse estudo desvelam a necessidade de permeabilizar os espaços de gestão de políticas públicas, em especial aquelas direcionadas a populações específicas situadas "do outro lado da linha”, para a produção de efetivos encontros interculturais e, a partir destes, de novos conceitos e sínteses. A contribuição da presença indígena demonstrou ser possível a construção de práticas menos desiguais e mais contextualizadas nos espaços de gestão, mais bem situadas diante da diversidade cultural e epistemológica dos diferentes povos e nas suas múltiplas estratégias de existência, apesar dos limites institucionais.

Reconhecer que vivemos em um lugar multicultural é admitir que são múltiplos os lugares de fala e de produção de conhecimento e que eles estão em permanente contato. Manter entre os sujeitos deste estudo uma postura "descuidada" em relação a esse contexto intercultural reforça a perspectiva de negação dos aspectos diacríticos do ser indígena, especialmente no Nordeste brasileiro, constrange estratégias autóctones de fortalecimento das práticas e costumes tradicionais desenvolvidas no âmbito do processo de etnogênese e terminam por outorgar o Estado brasileiro a persistir na atrofia das conquistas dos povos indígenas, acentuando sua situação de vulnerabilidade biológica, econômica e social.

É necessário avançar na incorporação dos direitos dos povos indígenas no Brasil no sentido de superar o uso de termos genéricos, esvaziados de conteúdo e eficazes na perpetuação das desigualdades epistêmicas e relações coloniais de poder, bem como na sustentação das linhas abissais que produzem como ausentes as distintas cosmovisões, crenças, filosofias e princípios de vida e sociedade.

A elaboração de conceitos potentes e textos institucionais claros, capazes de traduzir os diferentes contextos e culturas em diretrizes para o desenvolvimento de competências cognitivas relativas a um modo de pensar complexo, sensível e emancipatório deve contribuir para a superação da polissemia em torno do princípio da atenção diferenciada, e das consequentes distorções em torno da sua aplicação, e subsidiar ações para o enfrentamento dos principais processos responsáveis pela manutenção das desigualdades. 


\section{Referências}

ARRUTI, J. M. Etnogêneses indígenas. In: RICARDO, B.; RICARDO, F. Povos indígenas no Brasil: 2001-2005. São Paulo: Instituto Socioambiental, 2006. p. 50-54.

BOCCARA, G. La interculturalidad en Chile: entre culturalismo y despolitización. In: LANGDON, E. J.; CARDOSO, M. D. (Org.). Saúde indígena: políticas comparadas na América Latina. Florianópolis: Editora UFSC, 2015. p. 193-216. BRASIL. Projeto de Lei ${ }^{\circ} 4.681$, de 1994. Dispõe sobre as condições e funcionamento de serviços de saúde para as populações indígenas. Brasília, DF: Senado Federal, 1994. Disponível em: <https:// goo.gl/Rth5w7>. Acesso em: 3 jan. 2013.

BRASIL. Lei nº 9.836, de 23 de setembro de 1999. Acrescenta dispositivos à Lei no 8.080 , de 19 de setembro de 1990, que dispõe sobre as condições para a promoção, proteção e recuperação da saúde, a organização e o funcionamento dos serviços correspondentes e dá outras providências, instituindo o Subsistema de Atenção à Saúde Indígena. Diário Oficial da União, Brasília, DF, 23 set. 1999. Disponível em: <http:// bit.ly/2FGu2m7>. Acesso em: 9 abr. 2017.

BRASIL. Ministério da Saúde. Política Nacional de Atenção à Saúde dos Povos Indígenas. 2. ed. Brasília, DF: Fundação Nacional de Saúde, 2002. Disponível em: <http://bit.ly/2p5mEdN>. Acesso em: 12 mar. 2014.

BRASIL. Decreto $n^{0} 7 \cdot 508$, de 28 de junho de 2011. Regulamenta a Lei ${ }^{\circ} 8.080$, de 19 de setembro de 1990, para dispor sobre a organização do Sistema Único de Saúde - SUS, o planejamento da saúde, a assistência à saúde e a articulação interfederativa, e dá outras providências. Diário Oficial da União, Brasília, DF, 29 jun. 2011. Seção 1, p. 1.

BRASIL. Conselho Nacional de Secretários de Saúde. A integração da saúde indígena no SUS: uma proposta da gestão estadual. Brasília, DF, 2014. (Nota Técnica 4/2014). Disponível em: <http://bit.ly/2FQow3r>. Acesso em: 22 maio 2016.
CARVALHO, M. R.; CARVALHO, A. M. Índios e caboclos: a história recontada. Salvador: Edufba, 2012

CHAVES, M. B. G.; CARDOSO, A. M.; ALMEIDA, C. Implementação da política de saúde indígena no Pólo-Base Angra dos Reis, Rio de Janeiro, Brasil: entraves e perspectivas. Cadernos de Saúde Pública, Rio de Janeiro, v. 22, n. 2, p. 295-305, 2006.

DIASI - DIVISÃO DE ATENÇÃO À SAÚDE INDÍGENA. Relatório de atividades: DSEI Bahia. Salvador, 2017.

DIEHL, E. E.; LANGDON, E. J. Transformações na atenção à saúde indígena: tensões e negociações em um contexto indígena brasileiro. Universitas Humanística, Bogotá, n. 8o, p. 213-236, dez. 2015. Disponível em: <http://bit.ly/2pbxspY>. Acesso em: 13 abr. 2017.

FERNÁNDEZ-JUÁREZ, G. Sumak Kawsay: retos y paradojas de la Salud Intercultural. In: RODRIGUEZ, L.; NUÑEZ, E. Salud, interculturalidad y derechos: claves para la reconstrucción del Sumak Kawsay-Buen Vivir. Quito: Ministerio de Salud Pública, 2010. p. 17-52.

GARNELO, L. Política de saúde dos povos indígenas no Brasil: análise situacional do período de 1990 a 2004. Porto Velho: UFRO; ENSP, 2004. Disponível em: <http://bit.ly/2DoAhZC>. Acesso em: 22 jun. 2014.

GARNELO, L. O SUS e a saúde indígena: matrizes políticas e institucionais do Subsistema de Saúde Indígena. In: TEIXERA, C. C.; GARNELO, L. (Org.). Saúde indígena em perspectiva: explorando suas matrizes históricas e ideológicas. Rio de Janeiro: Fiocruz, 2014. p. 107-142.

GARNELO, L.; MACEDO, G.; BRANDÃO, L. C. Os povos indígenas e a construção das políticas públicas no Brasil. Brasília, DF: Opas, 2003.

IBGE - INSTITUTO BRASILEIRO DE GEOGRAFIA E ESTATÍSTICA. Censo Demográfico 2010: características gerais dos indígenas: resultados do universo. Rio de Janeiro, 2010. Disponível em: <http://bit.ly/2InEG2J >. Acesso em: 2 dez. 2016. 
IBGE - INSTITUTO BRASILEIRO DE GEOGRAFIA E ESTATÍSTICA. Os indígenas no Censo

Demográfico 2010: primeiras considerações com base no quesito cor ou raça. Rio de Janeiro, 2012. Disponível em: <http://bit.ly/2pgrIhn>. Acesso em: 8 maio 2016.

KIRMAYER, L. J.; ROUSSEAU, C.; GUZDER, J. Introduction: the place of culture in mental health services. In: KIRMAYER, L. J.; ROUSSEAU, C.; GUZDER, J. (Ed.). Cultural consultation: encountering the other in mental health care. New York: Springer, 2014. p. 1-20.

LANGDON, E. J. Uma avaliação crítica da atenção diferenciada e a colaboração entre antropologia e profissionais de saúde. In: LANGDON, E. J.; GARNELO, L. (Org.). Saúde dos povos indígenas: reflexões sobre antropologia participativa. Rio de Janeiro: Contra Capa, 2004. p. 33-51.

LANGDON, E. J. Diversidade cultural e os desafios da política brasileira de saúde do índio. Saúde e Sociedade, São Paulo, v. 16, n. 2, p. 7-9, 2007.

LANGDON, E. J. Os diálogos da antropologia com a saúde: contribuições para as políticas públicas em saúde indígena. In: LANGDON, E. J.; GRISOTTI, M. Políticas públicas: reflexões antropológicas. Santa Catarina: Edufsc, 2016. p. 17-42.

LANGDON, E. J.; DIEHL, E. E.; DIAS-SCOPEL, R. P. O papel e a formação dos agentes indígenas de saúde na atenção diferenciada à saúde dos povos indígenas brasileiros. In: TEIXEIRA, C. C.; GARNELO, L. Saúde indígena em perspectiva: explorando suas matrizes históricas e ideológicas. Rio de Janeiro: Fiocruz, 2014. p. 213-239.

LANGDON, E. J.; GRISOTTI, M.; MALUF, S. W. Reflexões antropológicas sobre as políticas públicas. In: LANGDON, E. J.; GRISOTTI, M. Políticas públicas: reflexões antropológicas. Santa Catarina: Edufsc, 2016. p. 7-14.

LUCIANO, G. S. O índio brasileiro: o que você precisa saber sobre os povos indígenas no Brasil de hoje. Brasília, DF: Ministério da Educação, 2006.

MAURO, V. F. Etnogênese e reelaboração da cultura entre os krahô-kanela e outros povos indígenas. Espaço Ameríndio, Porto Alegre, v. 7, n. 1, p. 37-94, 2013. Disponível em:

<http://bit.ly/2IoU2Eu>. Acesso em: 11 jun. 2015.

MEDEIROS, R. P. Política indigenista no período pombalino e seus reflexos nas capitanias do norte da América portuguesa. In: OLIVEIRA, J. P. A presença indígena no Nordeste: processos de territorialização, modos de reconhecimento e regimes de memória. Rio de Janeiro: Contra Capa, 2011. p. 115-144.

MENDONÇA, R. F. Reconhecimento em debate: os modelos de Honneth e Fraser em sua relação com o legado Habermasiano. Revista de Sociologia e Política, Curitiba, n. 29, p. 169-185, nov. 2007. Disponível em <http://bit.ly/2HwotqY>. Acesso em: 28 maio 2016.

MENÉNDEZ, E. L. Interculturalidad, “diferencias" y Antropología “at home”: algunas cuestiones metodológicas. In: JUÁREZ, G. F. Salude interculturalidad en América Latina: antropología de la salud y crítica intercultural. Quito: Abya Yala, 2006. p. 51-66.

NEVES, P. S. C. Luta Anti-racista: entre reconhecimento e redistribuição. Revista Brasileira de Ciências Sociais, v. 20, n. 59, p. 8196, 2005. Disponível em: <http://bit.ly/2Dpf4yT>. Acesso em: 22 maio 2016.

OLIVEIRA, J. P. A presença indígena no Nordeste: processos de territorialização, modos de reconhecimento e regimes de memória. Rio de Janeiro: Contra Capa, 2011.

SANTOS, B. S. Para um novo senso comum: a ciência, o direito e a política na transição paradigmática. In: SANTOS, B. S. A crítica da razão indolente: contra o desperdício da experiência. São Paulo: Cortez, 200oa. p. 15-22.

SANTOS, B. S. Por que é tão difícil construir uma teoria crítica? In: SANTOS, B. S. A crítica da razão indolente: contra o desperdício da experiência. São Paulo: Cortez, 20oob. p. 23-37.

SANTOS, B. S. Para além do pensamento abissal: das linhas globais a uma ecologia dos saberes. In: SANTOS, B. S.; MENESES, M. P. (Org.). Epistemologias do Sul. Coimbra: Almeidina, 2009. p. 23-72. 
SANTOS, B. S. Um discurso sobre as ciências. São Paulo: Cortez, 2010.

SANTOS, B. S.; NUNES, J. A. Introdução: para ampliar o cânone do reconhecimento, da diferença e da igualdade. In: SANTOS, B. S. Reconhecer para libertar: os caminhos do cosmopolitismo multicultural. Rio de Janeiro: Civilização Brasileira, 2003. p. 25-78.

TAVARES, L. H. D. História da Bahia. 11. ed. Salvador: Edufba, 2009.
VERDUM, R. Povos indígenas no Brasil: o desafio da autonomia. In: VERDUM, R. (Org.). Povos indígenas: constituições e reformas políticas na América Latina. Brasília, DF: Instituto de Estudos Socioeconômicos, 2009. p. 91-112.

WALSH, C. Interculturalidade crítica e pedagogia decolonial: in-surgir, re-existir e re-viver. In:

CANDAU, V. M. (Org.). Educação intercultural na América Latina: entre concepções, tensões e propostas. Rio de Janeiro: 7 Letras, 2009. p. 12-42.

\section{Contribuição das autoras}

Mota foi responsável pela concepção do estudo e análise dos dados. Nunes contribuiu para a discussão dos resultados. Ambas as autoras contribuíram para a redação do artigo.

Recebido: 20/11/2017

Reapresentado: 21/02/2018

Aprovado: 01/03/2018 